\title{
The Dark Side of Creativity: Original Thinkers Can Be More Dishonest
}

\section{Citation}

Gino, F., and D. Ariely. "The Dark Side of Creativity: Original Thinkers Can Be More Dishonest." Journal of Personality and Social Psychology 102, no. 3 (March 2012): 445-459.

\section{Permanent link}

http://nrs.harvard.edu/urn-3:HUL.InstRepos:10996803

\section{Terms of Use}

This article was downloaded from Harvard University's DASH repository, and is made available under the terms and conditions applicable to Open Access Policy Articles, as set forth at http:// nrs.harvard.edu/urn-3:HUL.InstRepos:dash.current.terms-of-use\#OAP

\section{Share Your Story}

The Harvard community has made this article openly available.

Please share how this access benefits you. Submit a story.

\section{Accessibility}




\title{
Running Head: CREATIVITY AND DISHONESTY
}

The Dark Side of Creativity: Original Thinkers Can be More Dishonest

\author{
Francesca Gino \\ Harvard Business School, Harvard University
}

Dan Ariely

Fuqua School of Business, Duke University

Forthcoming, Journal of Personality and Social Psychology

The authors are grateful to Max Bazerman and Ting Zhang for their insightful feedback on earlier drafts of the paper. The authors thank Associate Editor Leaf Van Boven, and three anonymous reviewers for substantive comments that significantly shaped this manuscript. The authors greatly appreciate the support and facilities of the Computer Lab for Experimental Research at Harvard Business Scholl and the Center for Decision Research at the University of North Carolina at Chapel Hill. Address correspondence to fgino@ hbs.edu. 


\begin{abstract}
Creativity is a common aspiration for individuals, organizations, and societies. Here, however, we test whether creativity increases dishonesty. We propose that a creative personality and a creative mindset promote individuals' ability to justify their behavior, which, in turn, leads to unethical behavior. In five studies, we show that participants with creative personalities tended to cheat more than less creative individuals, and that dispositional creativity is a better predictor of unethical behavior than intelligence (Experiment 1). In addition, we find that participants who were primed to think creatively were more likely to behave dishonestly than those in a control condition (Experiment 2) and that greater ability to justify their dishonest behavior explained the link between creativity and increased dishonesty (Experiments 3 and 4). Finally, we demonstrate that dispositional creativity moderates the influence of temporarily priming creativity on dishonest behavior (Experiment 5). The results provide evidence for an association between creativity and dishonesty, thus highlighting a dark side of creativity.
\end{abstract}

Key words: creativity, creative thinking, ethics, dishonesty, morality, moral flexibility, intelligence, unethical behavior 
"Evil always turns up in this world through some genius or other."

- Denis Diderot (1713-1784)

The ability to generate novel ideas and think creatively about problems has long been considered an important skill for individuals, as well as for organizations and societies. Creative thinking allows individuals to solve problems effectively (Mumford \& Gustafson, 1988) and to remain flexible (Flach, 1990) so that they can cope with the opportunities and changes in their day-to-day lives (Runco, 2004). At a more macro level, societies use new inventions, original scientific findings, and novel social programs to advance, and organizations need them to adapt to changing environments and succeed in the marketplace (Oldham \& Cummings, 1996; Goldenberg \& Mazursky, 2001; Goldenberg, Mazursky, \& Solomon, 1999). The important role of creativity in human progress and adaptation is likely one reason why scholars across disciplines long have been interested in understanding how creative thinking occurs and how it can be fostered (Simonton, 2003).

Creativity research in psychology has been conducted from different perspectives. Some work has focused on evaluating the creativity of products and individuals' accomplishments (e.g., Amabile, 1983; Baer, Kaufman, \& Gentile, 2004; Kaufman, Baer, Cole, \& Sexton, 2008; Plucker, \& Renzulli, 1999); other work has explored the cognitive and motivational processes that lead to creative ideas (e.g., Friedman \& Forster, 2001; Hirt, McDonald, \& Melton, 1996; Smith, Ward, \& Finke, 1995; Sternberg, 1999a) and the contextual factors that influence creative problem solving (e.g., Amabile, 1979; Forster, Friedman, \& Liberman, 2004; Galinsky \& Moskowitz, 2000; Markman, Lindberg, Kray, \& Galinsky, 2007; Maddux \& Galinsky, 2009); 
and still other research has examined the relationship between individuals' personality and their creativity (Kershner \& Ledger, 1985; for reviews, see Feist, 1998, 1999; Simonton, 2000, 2003).

Despite their varying focus, these approaches share a basic premise: because creativity improves problem solving and opens doors to new solutions and opportunities, creativity should be stimulated. But is creativity always beneficial? While the positive aspects of creativity have been praised and tested empirically (Goldenberg \& Mazursky, 2001; Sternberg, 1999a, 1999b), it is possible that creative thinking may also have a hidden cost in the form of increased dishonesty when used to resolve ethical dilemmas.

In the current research, we test for this possibility and propose that creativity has a dark side when applied to ethical behavior. We conduct five studies to examine whether there is a positive and reliable relationship between creativity and dishonesty, and to investigate the psychological mechanisms explaining this link.

\section{Creativity and Dishonest Behavior}

Creativity is defined as the ability to produce ideas that are both novel (i.e., original, unexpected) and appropriate (i.e., useful, adaptive to task constraints) (Amabile, 1983, 1988). Over the past several decades, researchers have explored many of the psychological factors that are considered vital to the creative process and have identified two main components underlying creative performance: divergent thinking (Guilford, 1968, 1982) and cognitive flexibility (Spiro \& Jehng, 1990). Divergent thinking refers to the ability of individuals to develop original ideas and to envision multiple solutions to a given problem. It involves thinking "without boundaries," or "outside the box" (Thompson, 2008, p. 226). Cognitive flexibility, by contrast, describes the ability of individuals to restructure knowledge in multiple different ways depending on changing situational demands (i.e., the complexity of the situation). 
Typically operating together, divergent thinking and cognitive flexibility help people find creative solutions to difficult problems, which may be interpreted from different points of view. One such context is provided by ethical dilemmas. Ethical dilemmas often require people to weigh two opposing forces: the desire to maximize self-interest and the desire to maintain a positive view of oneself (Mead, Baumeister, Gino, Schweitzer, \& Ariely, 2009). Recent research has suggested that individuals tend to resolve this tension through self-serving rationalizations: they behave dishonestly enough to profit from their unethical behavior, but honestly enough to maintain a positive self-concept as honest human beings (Mazar, Amir \& Ariely, 2008; Gino, Ayal \& Ariely, 2009). When facing the opportunity to behave dishonestly, in fact, most people cheat, if only by a little bit, but not as much as they possibly could (Ayal \& Gino, 2011; Gino et al., 2009). This "minor" cheating can be justified through various means. For instance, one might reason that other people would cheat under the same circumstances or that a little cheating won't hurt anyone.

Such self-serving justifications can help individuals convince themselves that their behavior is in fact morally appropriate and, as a result, that there is no need to negatively update their moral self-image. As a result, any situation in which there is room to justify potential dishonest or self-interested behavior is likely to promote dishonesty (Schweitzer \& Hsee, 2002; Shalvi, Dana, Handgraaf, \& De Dreu, 2011). This tendency to behave in a self-interested manner when the behavior in question can be justified was demonstrated years ago in a compelling study by Snyder, Kleck, Strenta, and Mentzer (1979). In the study, participants had to choose one of two rooms in which they would watch a movie with another person and then answer a short survey. In one room, the other person was physically handicapped; in the other room, the person was not. When the movie shown was the same in both rooms, participants were more likely to 
choose the room where they would sit with the handicapped person rather than the room where they would sit with the non-handicapped partner. But when different movies were projected in the two rooms, most people chose to avoid the stigmatized person since they could easily justify their choices.

Similarly, Schweitzer and Hsee (2002) conducted a negotiation study in which sellers of a car provided a buyer with a mileage estimate from a range of possible values and could lie about the estimate. The results indicated that sellers lied to a greater extent when the provided range was wide rather than narrow; they could justify the lie by using their increased uncertainty about the true mileage. Sellers processed the information about the car's mileage in a selfserving manner, allowing them to gain financially.

Thus, when individuals can easily generate justifications to reinterpret or rationalize unethical actions they are tempted to engage in, they will be more likely to behave dishonestly for monetary gains as compared to situations in which justifying the behavior is rather difficult. As noted by Kunda (1990), people reach the conclusions they want to reach, "but their ability to do so is constrained by their ability to construct seemingly reasonable justifications for these conclusions" (p. 480). Greater creativity, we suggest, facilitates this self-serving justification process. More specifically, we propose that when people are motivated to behave dishonestly so as to benefit financially in a given situation (or to advance their self-interest in other forms), divergent thinking is likely to help them develop original ways to bypass moral rules. Similarly, cognitive flexibility is likely to help them reinterpret available information regarding their own behavior in a self-serving way. Indeed, as prior research has suggested, creative people are able to perceive and describe what remains hidden from the view of others (Carson, Peterson, \& 
Higgins, 2003), and they are also able to develop original ideas and to envision multiple solutions to a given problem (Guilford, 1968, 1982).

As an example, consider a person's process of figuring out which tax deductions he is comfortable with and which lie beyond his ethically acceptable boundaries. A person who is highly creative or has been asked to think creativity about this task may be more likely to identify original steps to follow and to justify misreporting on taxes in novel ways. As this example illustrates, greater creativity may promote dishonesty in two ways. First, it can help individuals find creative loopholes to solve difficult tasks they are facing, even if that entails crossing ethical boundaries. ${ }^{1}$ Second, creativity may help individuals generate various credible reasons to justify their own actions before engaging in them - even when those actions are unethical. In this paper, we focus on this second direct consequence of creativity. In our studies, we employ tasks in which participants have the opportunity to behave dishonestly and are tempted to do so. We do not study whether participants cheat in more or less creative ways given a set of rules to complete the tasks. Rather, we focus on whether creativity influences the way people who are tempted to behave dishonestly justify their unethical actions.

In short, we expect creativity to be positively associated with dishonest behavior when people face ethical dilemmas (Hypothesis 1). In addition, we expect this relationship to hold both in the case of dispositional creativity and in the case of primes that temporarily trigger a creative mindset (Hypothesis 2). Several studies have demonstrated that simple primes can automatically activate certain goals and mindsets (Chartrand \& Bargh, 1996; Schaller, 2003), which, in turn, influence perception and behavior without explicit conscious awareness (Bargh, 1990; Bargh \&

\footnotetext{
${ }^{1}$ For instance, in the field of professional legal services, lawyers who are creative or are paid to think creatively often end up exploiting the loopholes and ambiguities of the law on behalf of clients, and their "creative compliance" with regulatory requirements undermines the purpose and effectiveness of existing regulations (McBarnet, 1988; McBarnet \& Whelan, 1991).
} 
Chartrand, 1999). For instance, Fitzsimons, Chartrand, and Fitzsimons (2008) found that participants primed with Apple logos (i.e., the logos of a company commonly associated with creativity and innovation) behaved more creatively on subsequent tasks as compared to participants primed with IBM logos and control participants. Finally, we suggest that creativity promotes dishonesty by increasing people's ability to self-justify their bad deeds (Hypothesis 3). That is, we propose that creativity increases moral flexibility, which we define as individuals' ability to justify their immoral actions by generating multiple and diverse reasons these actions can be judged as ethically appropriate.

\section{Overview of the Present Research}

We test our main hypotheses in a series of studies. First, as a pilot study, we collect field data to examine whether people in jobs that require high levels of creativity are more morally flexible than others. Next, we conduct five laboratory studies in which participants have the opportunity to behave dishonestly by overstating their performance and, as a result, earn more money. In Experiment 1, we measure creativity as an individual difference and examine whether this personality trait is associated with increased dishonest behavior. In Experiment 2, we prime cognitions associated with creativity and examine whether they temporarily promote dishonesty. In Experiments 3 and 4, we explore the mechanism explaining the link between creativity and dishonesty by focusing on people's ability to justify unethical behavior. Finally, in Experiment 5, we examine whether individual differences in creativity moderate the effect of priming a creative mindset on dishonesty.

Across all our studies, we consistently find that greater creativity promotes dishonesty by increasing individuals' ability to justify their unethical actions, both when considering measures of creative personality and when temporarily activating a creative mindset. 


\section{Pilot Study: Creativity and Dishonesty in the Field}

We started our investigation of the relationship between creativity and dishonesty by collecting data from an advertising agency located in the Southern United States. Ninety-nine employees (40 male; $M_{\mathrm{age}}=33.48, S D=8.16$ ) across 17 different departments within the same company responded to a short online survey.

First, respondents indicated how likely they would be to engage in each of eight ethically questionable behaviors (e.g., "Take home office supplies from work," "Inflate your business expense report"; $\alpha=.78$ ) on a seven-point scale ( $1=$ Not likely, $7=$ Very likely). Next, they read two scenarios describing a person who has the opportunity to behave dishonestly (from Gino, Norton, \& Ariely, 2010; see Appendix A) and then indicated how likely they would be to behave unethically if they were in the actor's shoes (using the same seven-point scale). Finally, respondents identified their department within the company and indicated how much creativity they thought was required on their job (on a 7-point scale, $1=$ Not at all, 7=Very much). Three managers in the executive office also provided ratings for the level of creativity required in each department (using a 10-point scale, 1=Not at all, 10=Very much),

We computed the z-scores for all the measures included in the study. As Table 1 shows, the creativity required on the job (as judged by both employees and managers) was positively correlated with employees' self-reported dishonesty. These results provide some preliminary evidence for the hypothesized association between creativity and dishonesty.

\section{Experiment 1: Effects of a Creative Personality}

Our first study tests the hypothesis that individuals who naturally have a more creative personality are also more likely to behave dishonestly. In addition, the study examines whether 
creativity as an individual difference is a better predictor of dishonesty than another dispositional factor often linked to creativity: intelligence.

While prior personality research has found a negative relationship between intelligence and academic cheating (Hetherington \& Feldman, 1964; Johnson \& Gormly, 1971), Sternberg (2001) proposed that there is a dialectical relationship between creativity and intelligence. In his view, intelligence is a necessary condition for creativity, which depends both on generation of novel ideas and critical analysis of them. If Sternberg's proposed positive relationship between intelligence and creativity does in fact exist, one might also wonder whether it is intelligence and not creativity that leads to dishonesty. Experiment 1 jointly tested the links between intelligence, creativity, and dishonest behavior.

\section{$\underline{\text { Method }}$}

Participants. Ninety-seven students from local universities in the Southeastern United States (45 male; $M_{\mathrm{age}}=21, S D=3.59$ ) enrolled in the study for payment. Participants were paid a \$2 show-up fee, \$3 for completing the online portion of the study, and then could earn an additional $\$ 20$ based on the choices they made throughout the study.

Procedure. A week before the lab portion of the study, participants completed an online survey that included dispositional measures of both intelligence and creativity. On the day they showed up at the lab, participants were told the study included three different tasks testing their problem-solving abilities, general knowledge, and perceptual skills, which had been combined for convenience. The three tasks were a perceptual task, a problem-solving task, and a multiplechoice task. We randomized the order in which these tasks were presented to participants. Each task provided participants with the opportunity to cheat. 
We used multiple measures of creativity and intelligence as well as various tasks to assess cheating to test the robustness of our proposed relationship between creativity as an individual difference and dishonesty.

\section{$\underline{\text { Dispositional Measures }}$}

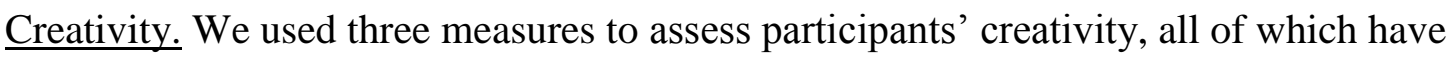
been shown to robustly predict creative performance (e.g., Barron \& Harrington, 1981; Feist, 1999; Gough, 1979; Tierney \& Farmer, 2002; Zhou \& Oldham, 2001). The first measure was Gough's creative personality scale (Gough, 1979). This measure asked participants to choose adjectives that best described them from a list of 30 adjectives. The scoring key was such that participants received a point every time they checked an adjective related to creative personality (e.g., insightful, inventive, original, resourceful, unconventional).

The second measure consisted of Hocevar's creative behavior inventory (Hocevar, 1980). This inventory includes a list of 77 activities and accomplishments that are considered to be creative (e.g., painted an original picture, wrote an original computer program, excluding school or university work). For each item, participants indicated the frequency of the behavior in their adolescent and adult life. The scoring rule was to sum up each participant's ratings for the activities included in the inventory.

Finally, the third measure of creative personality was a five-item scale assessing an individual's creative cognitive style (Kirton, 1976). The scale included items such as "I have a lot of creative ideas" and "I prefer tasks that enable me to think creatively" $(\alpha=.82)$. Participants indicated the extent to which they agreed with each item on a seven-point scale ( $1=$ strongly disagree, $7=$ strongly agree). The scoring rule was to average each participant's ratings across the items. 
Intelligence. As for intelligence, we used two different measures. The first measure was the Cognitive Reflection Test (CRT), which consisted of three questions testing individuals' reliance on logic versus intuition; the questions are correlated with IQ (Frederick, 2005). Each question presents an easy "intuitive" answer that is actually incorrect. For instance, one of the questions asked "A bat and a ball cost $\$ 1.10$ in total. The bat costs $\$ 1.00$ more than the ball. How much does the ball cost?" One might intuitively but incorrectly say, "\$0.10." A person who is more thorough might respond that the ball actually costs $\$ 0.05(.05+(1+.05)=1.1)$. Those with higher IQs tend to notice that the intuitive answer contains inconsistencies that deserve a further (and more time-consuming) examination.

The second measure used was the Mill Hill Vocabulary Scale, which assesses verbal intelligence (Raven, Raven, \& Court, 1998). In this task, participants were presented with a series of ten words (e.g., dwindle, palliate); for each word, they were asked to choose which of six answer options was closest in meaning to the target word.

$\underline{\text { Tasks }}$

Perception task. In the visual perception task (developed by Gino et al., 2010), participants were presented with a square that was divided into two triangles by a diagonal line. In each trial, a total of 20 dots appeared inside the square for one second and then disappeared. The dots were distributed between the two triangles, and the participants had to identify which of the two triangles (right or left) contained more dots by clicking either on a button labeled "more on left" or on a button labeled "more on right." Each trial included a square with a different number of dots in the left and right triangles.

The instructions participants received explained how the task worked and gave them an example. The instructions informed participants that their task was "to indicate whether there 
were more dots on the right side of the square or on the left side of the square" in each round. They were also informed that a dot might sometimes be on the box's diagonal line.

Importantly, the payout in each trial was determined by the following rule: For each left decision ("more on left"), participants earned 0.5 cents, while for each right decision ("more on right”), they earned ten times as much (i.e., 5 cents). Using this payment structure, on every trial where there were more dots on the left, the task presented a conflict between providing an accurate answer (indicating left) and profit maximization (indicating right). Thus, this payment structure triggered a motivation to find more dots on the right side, given that participants received the payoff simply on the basis of their responses ("more on the left" or "more on the right") and not on the basis of accuracy.

To make sure participants understood the task, they first played a few practice trials with no payment. Once the task was clear, participants played 200 trials (which were based on two blocks of 100 identical trials) on which they earned real money. On each trial, they received feedback about their earnings on that trial and on their cumulative earnings up to that point.

In 50 of the trials (out of each block of 100), it was clear that one triangle had more dots than the other, while in the remaining 50 trials, it was somewhat ambiguous whether there was a larger number of dots in the left or right triangles (see Figure 1 for examples). We refer to these trials as "ambiguous," and we focus on them in our analysis since these are the trials that allowed for self-serving interpretation of the position of the dots. In each ambiguous trial, the participants could benefit from cheating by creatively misinterpreting the ambiguous information they were asked to evaluate. That is, participants could intentionally misrepresent their actual perception of these ambiguous trials and report "more on the right" simply because they realized that by doing so they would earn a higher payoff. Thus, we use these ambiguous trials to measure dishonesty. 
Given the structure of this task, participants could earn a maximum of $\$ 10$ on this perceptual task (by always pressing the "more on the right" button). Upon completion of this task, participants reported their performance as indicated on the computer on a collection slip, which they were to hand to the experimenter at the end of the study so they could be paid. ${ }^{2}$

Problem-solving task. For the problem-solving task, each participant received two sheets of paper. The first was a worksheet containing 20 matrices, each based on a set of 12 three-digit numbers (e.g., 5.78, see Mazar et al., 2008). The second sheet was a collection slip on which participants were asked to report their performance. In this task, participants had five minutes to find two numbers per matrix that added up to 10, but this duration was not sufficient for anyone to solve all 20 matrices. For each pair of numbers correctly identified, participants received $\$ 0.25$ (for a maximum payment of $\$ 5$ ). After the five minutes had passed, participants were told to fold their worksheets and place them in a recycling box positioned in a corner of the room; next, they were asked to write down their performance scores on their collection slips. There were no identifiers on the worksheets, thus allowing participants to feel anonymous as they reported their performance on the task. However, we changed the last two digits in one of the matrices on the worksheet and in the example provided on the back of the collection slip so that we could compare actual to reported performance.

Multiple-choice task. This task consisted of a general knowledge quiz with 50 multiplechoice questions of varying difficulty (e.g., How far can a kangaroo jump? What is the capital of Italy?). Participants received $\$ .10$ per correct answer (for a maximum payment of $\$ 5$ ). The experimenter told them to circle their answers on their question sheet and explained that they

\footnotetext{
${ }^{2}$ Although we use this task to assess cheating, choosing an answer that assures higher levels of payment could reflect motivated perception (Balcetis \& Dunning, 2006). That is, participants may perceptually disambiguate what they see on the screen to serve their goal to earn more money. We acknowledge this limitation, which is in part alleviated in this study by the use of multiple tasks to assess dishonest behavior.
} 
would transfer their answers to a bubble sheet after finishing. When participants finished the quiz, the experimenter told them that, by mistake, she had photocopied bubble sheets that already had the correct answers lightly marked on them. She then asked the participants to use these premarked bubble sheets, recycle the test sheets with their original responses, and submit the bubble sheets for payment. From these instructions, it was clear that participants could use the premarked bubble sheets to cheat when transferring their responses. However, as in the previous task, we were able to determine the extent of cheating by including a unique ID on both the test sheet and the bubble sheet.

\section{$\underline{\text { Pilot Study }}$}

We recruited a non-overlapping group of participants $\left(N=46, M_{\text {age }}=21.26, S D=1.84\right)$ and conducted a pilot study to examine whether participants would perceive the payment used in Experiment 1 as fair. In addition, we tested whether participants would consider cheating on the tasks employed in Experiment 1 as unethical and morally wrong. We asked participants in this pilot study to follow the same procedure as in the laboratory portion of Experiment 1 (without the online survey) with only one difference. This time participants did not have the opportunity to cheat in any of the three tasks. We used the same payment structure as in the lab portion of Experiment 1 (i.e., \$2 show-up fee, plus additional payment based on performance throughout the study). Upon completion of the study, we asked them two questions. First, we asked them to evaluate whether the payment structure used in the study was fair compared to other studies they may have participated in (1=not fair at all, 4=fair, $7=$ more than fair). Second, we asked them to imagine having the opportunity to self-report performance in each of the three tasks included in the study they had just completed and thus cheat for more money. For this question, participants 
indicated the extent to which over-reporting performance on the tasks would be morally wrong and unethical $(\alpha=.73)$ using a seven-point scale ( $1=$ not at all, $4=$ =somewhat, $7=$ extremely).

On average, participants earned $\$ 11.24(S D=1.26)$ in this pilot study, which lasted about 45-60 minutes. They reported the payment to be fair $(M=4.20, S D=0.98)$, and indicated that overstating performance on the tasks included in the experiment would be unethical $(M=5.11$, $S D=0.76$; a rating significantly higher than the scale mid-point, $t[45]=9.46, p<.001)$. Together, these results suggest that any evidence of dishonesty in Experiment 1 would occur in a context in which participants perceive their payment as fair and construe the tasks as ethical dilemmas.

\section{$\underline{\text { Results and Discussion }}$}

As Table 2 shows, the three measures of creative personality were significantly and positively correlated with one another, as were the two measures of intelligence. The measures of creative personality were also positively and significantly correlated with the level of dishonesty on each of the three tasks included in the study. ${ }^{3}$ However, we did not find evidence of a link between creativity and intelligence, nor a link between intelligence and dishonesty.

Next, we computed a z-score for each of our measures and averaged the individual scores to create one composite measure for creative personality, intelligence, and extent of dishonesty. ${ }^{4}$ We used this aggregate measures in a regression analysis testing whether dispositional creativity predicted dishonesty while controlling for intelligence. This analysis revealed that creativity as an individual difference was positively and significantly associated with dishonesty $(B=.48$, [SE=.084], $\beta=.51, t=5.73, p<.001)$ while intelligence was not $(\mathrm{B}=.059,[\mathrm{SE}=.086], \beta=.062$,

\footnotetext{
${ }^{3}$ For the visual perception task, we conducted further analyses to examine cheating on unambiguous trials. We found that it was highly correlated with cheating on ambiguous trials $(r=.91, p<.001)$ and moderately correlated with creative personality (Gough's creative personality: $r=.27, p<.01$; Creative cognitive style: $r=.19, p=.069$; Hocevar's creative behavior inventory: $r=.19, p=.065)$. However, cheating on unambiguous trials was not correlated with intelligence (Cognitive refection test score: $r=.04, p=.72$; Mill vocabulary test score: $r=-.02, p=.87$ ).

${ }^{4} \mathrm{We}$ also created z-scores for participants' actual performance on the problem-solving task and the multiple-choice task and found they were not correlated with dispositional creativity $(r=.15, p=.15$ and $r=-.06, p=.59$, respectively).
} 
$t=.695, p=.49)$. These results provide support for our hypothesis that dispositional creativity promotes dishonesty.

\section{Experiment 2: Creative Mindset and Dishonesty}

In Experiment 2, we examine whether activating a creative mindset temporarily promotes dishonest behavior in the same way a creative personality does.

\section{$\underline{\text { Method }}$}

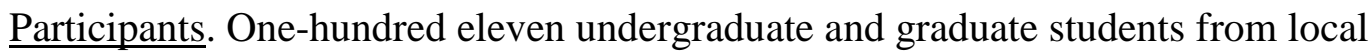
universities in the Southeastern United States (52 male; $M_{\mathrm{age}}=23.27, S D=3.32$ ) participated in the study for payment. They were paid a $\$ 4$ show-up fee and could earn an additional $\$ 10$ based on their reported performance.

Procedure. Participants engaged in three presumably unrelated tasks: a creativity prime (our manipulation) followed by a two-minute filler task, a creativity task (used as a manipulation check), and the matrix task employed in Experiment 1 (used to assess dishonest behavior).

Creativity prime. Participants were randomly assigned to one of two priming conditions: creative mindset vs. control. Previous research has successfully employed priming to activate a creative mindset (e.g., Fitzsimons et al., 2008; Sassenberg \& Moskowitz, 2005). We employed a scrambled sentence test, a frequently used method (Bargh \& Chartrand, 1999; Chartrand \& Bargh, 1996) for manipulating respondents' momentary mindset. All participants were asked to construct grammatically correct four-word sentences (e.g., the sky is blue) from a set of five randomly positioned words (e.g., sky, is, the, why, blue). For the participants in the creativemindset condition, 12 of the 20 sentences included words related to creativity (creative, original, inventiveness, novel, new, innovative, invention, creativity, ingenious, imagination, originality, 
and ideas), while for the participants in the control condition, no words related to creativity were included. This priming task was followed by a two-minute filler task to distract participants. Manipulation check. We measured creativity triggered by the prime using the Duncker candle problem. Participants were shown a picture containing several objects on a table: a candle, a pack of matches, and a box of tacks, all of which were next to a cardboard wall (see Figure 2). Participants were given three minutes "to figure out, using only the objects on the table, how to attach the candle to the wall so that the candle burns properly and does not drip wax on the table or the floor." The correct solution consists of emptying the box of tacks, tacking it to the wall, and placing the candle inside, so that the box of tacks is used as a candleholder. In this task, finding the correct solution is a measure of insight creativity because it involves the ability to see objects as performing atypical functions (i.e., the box of tacks can be used as a stand) (Duncker, 1945; Glucksberg \& Weisberg, 1966; Maddux \& Galinsky, 2009).

Problem-solving task. Next, participants completed the same problem-solving task with the 20 matrices used in Experiment 1. We assessed cheating on this task by computing the difference between participants' self-reported and actual performance.

Final questionnaire. Finally, participants filled out a questionnaire including demographic questions and post-experimental questions assessing their awareness of the priming (Bargh \& Chartrand, 2000). Participants were excluded from the data if they indicated awareness of the priming (e.g., "Something to do with creativity, originality, novelty"; "Words like creativity, originality used often") or the purpose of the experiment. No participant was disqualified under these exclusion criteria.

$\underline{\text { Results and Discussion }}$ 
Manipulation check. The percentage of participants who correctly solved the candle task was larger in the creative-mindset condition than in the control condition (47.3\% vs. $26.8 \%)$, $\chi^{2}(1, N=111)=5.00, p<.05$, suggesting that our priming manipulation was effective.

Cheating on the problem-solving task. The average number of matrices by which participants overstated their performance was greater in the creative-mindset condition $(M=2.71$, $S D=3.15)$ than in the control condition $(M=1.09, S D=1.98), t(109)=3.25, p<.01 .{ }^{5}$ Furthermore, the percentage of participants who overstated their performance was also higher (49\% vs. 27\%, $\left.\chi^{2}[1, N=111]=5.87, p<.05\right)$.

Taken together, these results demonstrate that even when activated temporarily, a creative mindset promotes dishonesty.

\section{Experiment 3: The Power of Justifications}

So far, we have demonstrated that creativity promotes dishonesty when people face an ethical dilemma and are motivated to behave unethically, both when creativity is measured as an individual difference and when it is temporarily activated through priming. In Experiment 3, we investigate the psychological mechanism that may explain this relationship. We proposed that creativity promotes dishonesty by increasing people's ability to justify their unethical actions.

In Experiment 3, we test this hypothesis by manipulating a feature of the task participants completed so that they would have more or less room to justify dishonesty. The less room the task provides for justifying cheating, the more moral flexibility individuals will need if they are to behave dishonestly on that task without feeling too guilty about their actions. We expect creativity to be particularly conducive to cheating on those tasks since it enhances moral

\footnotetext{
5 Participants' actual performance on the problem-solving task did not differ across conditions $\left(M_{\text {creative-minset }}=7.31\right.$, $S D=2.05$ vs. $\left.M_{\text {control }}=7.20, S D=2.24\right), t(109)<1, p=.78$.
} 
flexibility. By contrast, on tasks that provide room for justification by design, creativity may be less "beneficial" for dishonesty since moral flexibility is not needed to justify cheating.

$\underline{\text { Method }}$

Participants. One-hundred forty-five individuals from a city in the Northeastern United States (57 male; 112 students; $M_{\text {age }}=22.41, S D=2.81$ ) participated in a series of unrelated studies for $\$ 20$. Our study was the first one the participants completed.

Design and procedure. The study employed two between-subjects factors: prime (control vs. creative) and room for justification (high vs. low). As their first task, participants completed the sentence scramble task used in Experiment 2 and were thus exposed to either a creative prime or a control prime. Next, they completed the Remote Association Task (RAT, Mednick, 1962), a measure commonly used to assess creativity by assessing people's ability to identify associations between words that are normally associated. In this task, participants are asked to find a word that is logically linked to all of three words provided. For instance, "cold" is the common word linking the words "sore-shoulder-seat." Participants were given five minutes to solve 17 RAT items (see Appendix B).

As their next task, participants were asked to roll a six-sided die anonymously (a task adapted from Shalvi et al., 2011). For this task, they would earn money based on the reported outcome. Before the beginning of the study, the experimenter placed a plastic cup with a die in it on each desk. We introduced our second manipulation in this task. In the low-justification condition, participants were instructed to privately roll the die in the cup only once (by shaking the cup) and then report their outcome on the collection slip they had received. In the highjustification condition, participants instead were asked to roll the die a first time and then to roll it again a few more times to make sure the die was legitimate. After making sure the die was 
legitimate, participants had to report the outcome of the first roll. In both conditions, the bonus payment for this task varied with the outcome of the die roll: participants received $\$ 1$ if the outcome was $1, \$ 2$ if it was 2 , and so on, up to $\$ 6$ if the outcome of the die roll was 6 . This task gave participants the opportunity to lie by reporting an outcome higher than the one actually obtained on the first die roll.

Having the possibility to roll the die multiple times gives participants room to justify their potential lies (Shalvi et al., 2011). We used this justification manipulation to find evidence for the mechanism linking creativity and dishonest behavior through moderation. We predicted that rolling the die multiple times would moderate the relationship between a creative mindset and dishonesty. Specifically, in the low-justification condition, we expected greater lying in the creative-mindset condition than in the control condition. However, we expected this difference to become less prominent in the high-justification condition since individuals in a creative mindset already have the ability to generate reasons they can use to rationalize their unethical behavior. $\underline{\text { Results and Discussion }}$

Manipulation check. We used the number of correct responses on the RAT as our manipulation check to determine whether participants primed to think creatively were more likely to complete this creative task successfully. Participants in the creative-mindset condition performed better on the RAT $(M=8.41, S D=2.92)$ as compared to those in the control condition $(M=6.91, S D=2.94), t(143)=3.07, p=.003$. This result suggests that our priming was effective.

Die roll outcome. A 2 (prime) X 2 (justification) between-subjects ANOVA using the self-reported outcome of the die roll as the dependent measure revealed a significant interaction, $F(1,141)=4.05, p=.046, \eta_{p}^{2}=.03$ (see Figure 3). For participants in the low-justification condition, a creative mindset led to higher self-reported outcomes on the die roll compared to a neutral 
mindset $(F[1,141]=13.58, p<.001)$. However, for participants in the high-justification condition, the difference in reported outcomes between the creative-mindset and the neutral-mindset condition did not reach significance $(F[1,141]=1.49, p=.225)$. This analysis also revealed a main effect for both the prime manipulation $\left(F[1,141]=12.83, p<.001, \eta^{2}=.08\right)$ and the justification manipulation $\left(F[1,141]=5.50, p=.02, \eta^{2}=.04\right)$.

Together, these results provide evidence consistent with the hypothesis that creativity promotes dishonesty by increasing individuals' ability to generate reasons to justify their unethical behavior.

\section{Experiment 4: Justifications and Creative Personality}

The results of Experiment 3 suggest that moral flexibility explains the relationship between a creative mindset and increased dishonesty. In Experiment 4, we examine whether justifications play a similar role in explaining the link between a creative personality and increased dishonesty.

$\underline{\text { Method }}$

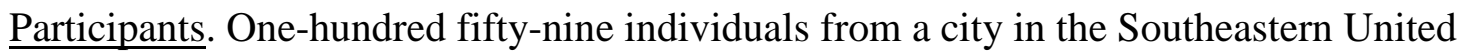
States (89 male; 111 students; $M_{\text {age }}=25.38, S D=4.62$ ) participated in the study. They were paid $\$ 4$ for completing an online survey and could earn up to \$6 during the lab component of the study (in addition to potential earnings related to other studies occurring in the same session). Participants were randomly assigned to one of two conditions: high vs. low justification.

Procedure. The study employed the same procedure as in Experiment 3 with two main differences. First, participants completed an online survey a week prior to the lab session. The survey included the same three measures assessing creativity employed in Experiment 1, and a measure assessing narcissism as a personality trait. We measured narcissism by using the 16- 
item Narcissistic Personality Inventory (NPI-16) developed by Ames, Rose and Cameron (2006). This is a forced-choice measure, which includes items as "I really like to be the center of attention" and "I insist upon getting the respect that is due to me." We included a measure for narcissism because prior research has demonstrated that people who think they are more creative than others also tend to be narcissists (Goncalo, Flynn, \& Kim, 2010). Thus, it is important to show that the link between dispositional creativity and dishonest behavior we observed in Experiment 1 holds even when controlling for narcissism. The survey also included the RAT (the same 17 items as in Experiment 3). Second, differently from Experiment 3, this study only included the justification manipulation and not the priming one.

Consistent with the results of Experiment 3, we expected that having room to justify potential lies would moderate the effects of dispositional creativity on dishonesty. In particular, we predicted that the relationship between creativity as an individual difference and dishonesty would be stronger in the low-justification condition than in the high-justification condition. $\underline{\text { Results and Discussion }}$

Creative personality and creative performance. We first examined whether participants who scored high on dispositional creativity also performed better on the RAT. As shown in Table 3, this was in fact the case. Next, we conducted a regression analysis using a composite zscore for the measures of creative personality as predictor of RAT performance while controlling for narcissism. Consistent with the correlations reported in Table 3, we found that a creative personality predicted creative performance on the $\mathrm{RAT}(\mathrm{B}=1.95$, [SE=.41], $\beta=.37, t=4.70$, $p<.001)$. Narcissism did not ( $\mathrm{B}=.03,[\mathrm{SE}=.32], \beta=.007, t=.095, p=.93)$.

Die roll outcome. Next, we examined whether our justification manipulation moderated the relationship between dispositional creativity and higher self-reported outcomes on the die roll 
(which are suggestive of lying). We tested this hypothesis using the moderated regression procedures recommended by Aiken and West (1991). In our regression analysis, we controlled for narcissism. As shown in Table 4, we found a significant interaction between the composite measure of a creativity personality and the justification manipulation in predicting participants' self-reported outcome on the die roll $(\beta=-.20, p<.05)$. To interpret the form of the interaction, we plotted the simple slopes for the relationship between dispositional creativity and self-reported outcome on the die roll at each level of our justification manipulation (see Figure 4). When participants rolled the die one time only (low-justification condition), dispositional creativity was associated with higher self-reported outcomes on the die roll $(\beta=.56, p<.001)$. When participants rolled the die multiple times (high-justification condition), this association was still significant but was not as strong $(\beta=.27, p=.01)$.

These results suggest that a creative personality promotes dishonest behavior by increasing the ability of individuals to justify their (potential) unethical actions.

\section{Experiment 5: Doubling on Creativity}

Our first four studies demonstrated a robust relationship between creativity and dishonest behavior, when creativity was both assessed as an individual difference and experimentally manipulated. In addition, through moderation, we found that moral flexibility explains this link. We designed a final study to test whether dispositional creativity moderates the effect of priming a creative mindset on dishonest behavior. We predicted that dispositional creativity would moderate the impact of primed creativity on dishonesty such that those who are more dispositionally creative are less influenced by the creativity prime as compared to those who are less dispositionally creative.

\section{$\underline{\text { Method }}$}


Participants. One-hundred eight students from local universities in the Southeastern United States (53 male; $M_{\text {age }}=21.94, S D=3.33$ ) participated in the study for pay. They were paid a $\$ 2$ show-up fee, $\$ 4$ for completing an online survey, and could earn an additional \$10 based on their performance in the study.

Design and procedure. We used the same design and procedure as in Experiment 2, with only one difference. In addition to attending the session in the laboratory, participants completed an online survey with the three measures of creative personality we used in Experiments 1 and 4. $\underline{\text { Results and Discussion }}$

Means, standard deviations, and correlations for the three creativity variables appear in Table 5. We created individual z-scores for each of these measures and then averaged them into an aggregate measure for dispositional creativity.

We tested whether a creative personality moderates the effect of priming a creative mindset on both creative performance and on dishonest behavior, following the moderated regression procedures recommended by Aiken and West (1991). Table 6 displays the results of our regression analyses. As we predicted, there was a significant interaction between our prime manipulation and dispositional creativity in predicting creative performance $(\mathrm{B}=-1.31$ [SE=.61], Wald $=4.65, p=.031$ ), the amount of cheating (i.e., the percentage of participants who cheated, $\mathrm{B}=-1.12[\mathrm{SE}=.56]$, Wald=3.94, $p=.047$ ), and the extent of cheating (i.e., the degree to which participants cheated, $\mathrm{B}=-1.67$ [SE=.84], $t=-1.99, p=.049$ ) (see Figure 5).

When participants scored low on (the aggregated measure of) dispositional creativity, a creative mindset was associated with higher levels of creative performance $(\beta=.55, p=.001)$, and greater cheating $(\beta=.52, p=.001$ for the decision to cheat and $\beta=.48, p=.003$ for the extent of cheating, respectively). By contrast, when individuals scored high on dispositional creativity, a 
creative mindset was no longer associated with higher creative performance $(\beta=.05, p=.73)$, nor with greater cheating $(\beta=.03, p=.87$ for the decision to cheat, and $\beta=-.02, p=.89$ for the extent of cheating, respectively).

These results show that dispositional creativity moderates the relationship between priming a creative mindset and creative performance, as well as the relationship between priming a creative mindset and dishonest behavior.

\section{General Discussion}

Over the last three decades, an increasing number of studies have highlighted the importance of creativity for individuals, organizations, and societies. The majority of this work has stressed the potential and real benefits of creative thinking. For instance, research has shown that creative products generate an average return that is significantly higher than that of “common" products (Horibe, 2001), and investments in creativity and innovation positively impact organizational performance (Lev, 2004). Creativity is also beneficial at the individual level, as it helps us manage our daily lives and find creative solutions to both ordinary and difficult problems.

This paper casts a shadow on the widespread view that creativity always leads to "good." In five studies, we demonstrated that creativity might also produce negative effects by leading individuals to more frequently engage in dishonest behavior. An initial pilot study conducted in the field demonstrated that employees who are in positions that require creativity are more likely to be morally flexible and engage in wrongdoing in the workplace. Experiment 1 found a significant relationship between creative personality and dishonesty, and demonstrated that creativity is a better predictor of dishonest behavior than intelligence. Experiment 2 showed that participants primed with a creative mindset were more likely to cheat than were participants in a 
control condition. Experiments 3 and 4 explored the mechanism explaining this link and demonstrated that participants who were primed to think creatively (Experiment 3) or who were highly creative (Experiment 4) were more likely to behave dishonestly because of their greater ability to justify their dishonest behavior. Finally, in Experiment 5, we both assessed creativity through an individual difference measure and manipulated it experimentally through priming. This final study demonstrated that a creative personality moderates the effects of activating a creative mindset on dishonest behavior. Priming a creative mindset is the most beneficial means of enhancing creative thinking for individuals who score low (rather than high) on dispositional creativity.

\section{Theoretical Contributions}

The present research contributes to the creativity literature by offering new insights on the potential dark side of creative thinking. Prior work has identified several variables that significantly promote or inhibit creative performance and has argued for the importance of enhancing these factors with the primary goal of increasing creativity. Here, we highlight the potential unintended consequences of creativity. Greater creativity helps individuals solve difficult tasks across many domains, but creative sparks may lead individuals to take unethical routes when searching for solutions to problems and tasks.

Our work also contributes to research on moral psychology and ethical decision making. Our findings are consistent with studies highlighting the importance of psychological factors in driving people's dishonesty. An emerging literature has begun to identify when these oftensubtle factors influence decisions to behave unethically, both consciously and unconsciously (Chugh, Bazerman, \& Banaji, 2005; Gino \& Pierce, 2009; Mazar et al., 2008; Monin, Sawyer, \& Marquez, 2008; Jordan \& Monin, 2008; Shu, Gino, \& Bazerman, 2011; Tenbrunsel \& Messick, 
2004). Here, we extend this body of work by showing that greater creativity can lead to greater dishonesty by increasing individuals' ability to justify their immoral actions.

Our research speaks to existing work on elastic justification (Hsee, 1995, 1996). This research finds that unjustifiable factors (those we wish to take into consideration but know we should not) influence individuals' judgments more when there is ambiguity in the justifiable factors (those we believe we should take into consideration) than when there is not. Our studies demonstrate that this type of self-justification process occurs more easily when people have a creative personality or when they are in a creative mindset.

The findings of the present research can be evaluated with respect to work on moral credentials. According to moral credentialing theory (Monin \& Miller, 2001), when individuals become aware of their own moral deeds, they are more likely to act immorally on subsequent endeavors because they feel as if they earned "moral credits." Similarly, being able to generate several original justifications for one's own unethical actions thanks to creativity may lead people to feel licensed to cheat.

Finally, the present work plants a first step in a research domain that is highly relevant to the increasingly changing, innovative, and competitive world of the 21 st century. As innovation has increased, this century already has weathered a series of accounting scandals and the collapse of several billion-dollar companies, resulting in dramatic changes to the business landscape. Similarly, over the last decade, we have increasingly witnessed cases of academic dishonesty by both students and teachers, as well as scandals of scientific cheating. Dishonesty and innovation are two of the topics most widely written about in the popular press. Yet, to date, the relationship between creativity and dishonest behavior has not been studied empirically. We believe that understanding this relationship has several important implications for education, business, and 
policy. We are often surprised to learn that successful and ingenious decision makers in these contexts have crossed ethical boundaries. The results from the current paper indicate that, in fact, people who are creative or work in environments that promote creative thinking may be the most at risk when they face ethical dilemmas. Our work offers the first empirical demonstration of the association between creativity and dishonesty, as well as evidence of the important role of justifications in explaining this relationship.

\section{$\underline{\text { Limitations and Directions for Future Research }}$}

These contributions must be qualified in light of several important limitations of our research, which could be addressed by future work. First, in our studies we created situations in which participants were tempted to cheat. We used tasks that likely triggered a conflict between participants' short-term desire to earn undeserved money by cheating and their long-term desire to be ethical and thus not cheat. People commonly use self-control resources to resolve this type of conflict (Mead et al., 2009). Future research could investigate whether creativity would lead people to act in ways that satisfy their selfish, short-term desires rather than their higher goals when facing other types of self-control dilemmas, such as eating a slice of chocolate cake when trying to lose weight. As in the studies presented here, creativity may help individuals generate a variety of reasons to justify such self-serving behaviors.

Future research could also further examine whether creativity influences individuals' motivations to behave dishonestly as well as their ability to justify self-serving actions. Although our work focused on the effects of the latter, one could examine whether dispositional creativity and creative primes also increase individuals' desire to cheat. For instance, creativity may lead people to think of more and diverse ways they could benefit from the monetary gains from cheating, thus making cheating itself more tempting. Our studies did not specifically test for a 
link between creativity and the desire to cheat, but do provide evidence that is inconsistent with this alternative explanation. Indeed, the results of Experiments 3 and 4 demonstrate that creativity increases individuals' moral flexibility, thus increasing their ability to behave dishonestly. Thanks to greater creativity, people have more and diverse reasons to justify their own unethical behavior.

Future work could also examine how creativity may lead to different consequences when people face ethical dilemmas if they are not tempted by the possibility of behaving dishonestly to earn more money. In our studies, we used tasks that would heighten participants' desire to cheat. It is possible, however, that individuals may have different goals when facing ethical dilemmas. For instance, they may be motivated to behave consistently with their moral principles and standards. Depending on the salient goal driving individual behavior, creativity may results in actions that are prosocial rather than unethical, or actions that show moral courage. For instance, a negotiator may decide to disclose information that affects how much his counterpart thinks the issue being negotiated is worth, even if hiding the information would lead to a better deal for him. In this case, creativity would help the negotiators generate many different reasons why disclosing information is the proper action to take. Examining such possibility would further our understanding of the role of creativity in ethical decision making.

Finally, future research could investigate the boundary conditions of the effects observed in our studies and examine how people and organizations can foster creativity and benefit from individuals' creative sparks while avoiding unintended evil solutions. For instance, this research could manipulate the saliency of ethical standards (e.g., by using an ethics code), the strength of ethical norms, or the identity of moral exemplars, and examine whether these factors could be effectively used to combat the potential dark consequences of creativity. Similarly, future work 
could study the effects of creativity in groups and manipulate the level of competitiveness or cooperation within a group to examine whether promoting a climate of cooperation can reduce the effects of creativity on dishonest behavior.

By calling attention to a previously underexplored relationship, that between creativity and dishonesty, our studies have uncovered findings of both theoretical and practical importance. Scholars need more knowledge regarding both the positive and negative consequences of thinking outside the box before fully embracing the recommendation to stimulate creativity in organizations and society more broadly. We hope this research will stimulate future endeavors that can further our understanding of how the process of self-serving justifications, triggered by creativity primes or a creative personality, can lead to dishonest behavior.

\section{Conclusions}

In the current studies, we found a robust relationship between creativity and dishonesty. This research provides a critical first step toward understanding how creativity is associated with unethical behavior, two often-discussed phenomena in our complex world. Across five studies, we demonstrated that both a creative personality and an activated creative mindset promote individuals' ability to justify their unethical actions. In turn, this increased ability to justify potential unethical actions promotes dishonesty. Our results suggest that a link between creativity and rationalization. As Mazar et al. (2008) proposed, the ability of most people to behave dishonestly might be bounded by their ability to cheat and at the same time feel that they are behaving as moral individuals. To the extent that creativity allows people to more easily behave dishonestly and rationalize this behavior, creativity might be a more general driver of this type of dishonesty and play a useful role in understanding unethical behavior. 


\section{Appendix A}

\section{Scenarios used in the Pilot Study}

1. Steve is the Operations manager of a firm that produces pesticides and fertilizers for lawns and gardens. A certain toxic chemical is going to be banned in a year, and for this reason is extremely cheap now. If Steve buys this chemical, produces and distributes his product fast enough, he will be able to make a very nice profit. If you were Steve, how likely is it you would use this chemical while it is still legal?

2. Dale is the Operations manager of a firm that produces health food. Their organic fruit beverage has 109 calories per serving. Dale knows people are sensitive to crossing the critical threshold of one hundred calories. He could decrease the serving size by $10 \%$. The label will say each serving has 98 calories, and the fine print will say each bottle contains 2.2 servings. If you were Dale, how likely is it you would cut the serving size to avoid crossing the 100 threshold? 


\section{Appendix B}

\section{RAT items used in Experiments 3 and 4}

The goal in this task is to find a word that is logically linked to all three of the words provided. For example: (1) Manners Round Tennis $=$ Table (2) Playing Credit Report $=$ Card

Thus, the word "table" is a solution because it links the words "manners-round-table" (i.e. table manners, round table, table tennis). The word "card" is a solution because it links the words "playing-credit-report" (i.e. playing card, credit card, report card).

In the space below, try to solve as many items as you can. Work as fast as you can without sacrificing accuracy. YOU HAVE FIVE MINUTES (i.e., 300 seconds) TO WORK ON THIS. Please do not use any help other than your own knowledge.

\begin{tabular}{llll}
\hline \multicolumn{1}{c}{ Word 1} & \multicolumn{1}{r}{ Word 2} & \multicolumn{1}{c}{ Word 3} & Polution \\
\hline Blank & White & Lines & Paper \\
Magic & Plush & Floor & Carpet \\
Thread & Pine & Pain & Needle \\
Stop & Petty & Sneak & Thief \\
Envy & Golf & Beans & Green \\
Chocolate & Fortune & Tin & Cookie \\
Barrel & Root & Belly & Beer \\
Broken & Clear & Eye & Glass \\
Pure & Blue & Fall & Water \\
Widow & Bite & Monkey & Spider \\
Chamber & Staff & Box & Music \\
Mouse & Sharp & Blue & Cheese \\
Hall & Car & Swimming & Pool \\
Square & Cardboard & Open & Box \\
Ticket & Shop & Broker & Pawn \\
High & Book & Sour & Note \\
Gold & Stool & Tender & Bar \\
\hline
\end{tabular}




\section{References}

Amabile, T. M. (1979). Effects of external evaluation on artistic creativity. Journal of Personality and Social Psychology, 37, 221-233.

Amabile, T. M. (1983). The social psychology of creativity: A componential conceptualization. Journal of Personality and Social Psychology, 45, 357-376.

Amabile, T. M. (1988). A model of creativity and innovation in organizations. In Staw B. M., Cummings, L. L. (Eds.), Research in Organizational Behavior, 10, 123-167.

Ames, D., Rose, P., \& Anderson, C. P. (2006). The NPI-16 as a short measure of narcissism. Journal of Research in Personality, 40, 440-450.

Ayal, S., \& Gino, F. (2011). Honest rationales for dishonest behavior. In M. Mikulincer \& P. R. Shaver (Eds.), The Social Psychology of Morality: Exploring the Causes of Good and Evil. Washington, DC: American Psychological Association.

Baer, J., Kaufman, J. C., \& Gentile, C.A. (2004). Extension of the consensual assessment technique to nonparallel creative products. Creativity Research Journal, 16, 113-117.

Balcetis, E., \& Dunning, D. (2006). See what you want to see: Motivational influences on visual perception. Journal of Personality and Social Psychology, 91, 612-625.

Bargh, J. A. (1990). Auto-motives: Preconscious determinant of social interaction. In E. T. Higgins \& R. M. Sorrentino (Eds.), Handbook of motivation and social cognition: Foundations of social behavior (Vol. 2, pp. 93-130). New York: Guilford Press.

Bargh, J. A., \& Chartrand, T. L. (1999). The unbearable automaticity of being. American Psychologist, 54, 462-479.

Bargh, J. A., \& Chartrand, T. L. (2000). The mind in the middle: A practical guide to priming and automaticity research. In H. T. Reis \& C. M. Judd (Eds.), Handbook of research 
methods in social and personality psychology (pp. 253-285). New York: Cambridge University Press.

Barron, F. B., \& Harrington, D. M. (1981). Creativity, intelligence, and personality. Annual Review of Psychology, 32, 439-476.

Carson, S. H., Peterson, J. B., \& Higgins, D. M. (2003). Decreased latent inhibition is associated with increased creative achievement in high-functioning individuals. Journal of Personality and Social Psychology, 85(3), 499-506.

Chartrand, T. L., \& Bargh, J. A. (1996). Automatic activation of social information processing goals: Nonconscious priming reproduces effects of explicit conscious instructions. Journal of Personality and Social Psychology, 71, 464-478.

Chugh, D., Bazerman, M., \& Banaji, M. (2005). Bounded ethicality as a psychological barrier to recognizing conflicts of interest. In D. Moore, D. Cain, G. Loewenstein, \& M. Bazerman (Eds.), Conflict of interest: Challenges and solutions in business, law, medicine, and public policy (pp. 74-95). New York: Cambridge University Press.

Duncker, K. (1945). On problem solving. Psychological Monographs, 58 (5, Serial No. 270).

Feist, G. J. (1998). A meta-analysis of personality in scientific and artistic creativity. Personality and Social Psychology Review, 2(4), 290-309.

Feist, G. J. (1999). Personality in scientific and artistic creativity. In R. J. Sternberg (Ed.), Handbook of creativity (pp. 273-296). New York: Cambridge University Press.

Fitzsimons, G. M., Chartrand, T. L., \& Fitzsimons, G. J. (2008). Automatic effects of brand exposure on motivated behavior: How Apple makes you "think different." Journal of Consumer Research, 35, 21-35. 
Flach, F. (1990). Disorders of the pathways involved in the creative process. Creativity Research Journal, 3, 158-165.

Forster, J., Friedman, R., \& Liberman, N. (2004). Temporal construal effects on abstract and concrete thinking: Consequences for insight and creative cognition. Journal of Personality and Social Psychology, 87, 177-189.

Frederick, S. (2005). Cognitive reflection and decision making. Journal of Economic Perspectives, 19(4), 25-42.

Friedman, R. S., \& Forster, J. (2001). The effects of promotion and prevention cues on creativity. Journal of Personality and Social Psychology, 81, 1001-1013.

Galinsky, A. D., \& Moskowitz, G. B. (2000). Counterfactuals as behavioral primes: Priming the simulation heuristic and considerations of alternatives. Journal of Experimental Social Psychology, 36, 384-409.

Gino, F., Ayal, S., \& Ariely, D. (2009). Contagion and differentiation in unethical behavior: The effect of one bad apple on the barrel. Psychological Science, 20(3), 393-398.

Gino, F., Norton, M., \& Ariely, D. (2010). The counterfeit self: The deceptive costs of faking it. Psychological Science, 21(5), 712-720.

Gino, F., \& Pierce, L. (2009). Dishonesty in the name of equity. Psychological Science, 20(9), 1153-1160.

Glucksberg, S., \& Weisberg, W. R. (1966). Verbal behavior and problem solving: Effects of labeling in a functional fixedness problem. Journal of Experimental Psychology, 71, 659664.

Goldenberg, J., \& Mazursky, D. (2001). Creativity templates in new products. Cambridge University Press, NY. 
Goldenberg, J., Mazursky, D., \& Solomon, S. (1999). Creative sparks. Science, 285(5433) September, 1495-1496.

Goncalo, J. A., Flynn, F. J., Kim, S. H., (2010). Are two narcissists better than one? The link between narcissism, perceived creativity, and creative performance. Personality and Social Psychology Bulletin, 36(11), 1484-1495.

Gough, H. G. (1979). A creative personality scale for the adjective check list. Journal of Personality and Social Psychology, 37, 1398-1405.

Guilford, J. P. (1968). Intelligence, creativity, and their educational implications. New York: Robert R. Knapp.

Guilford, J. P. (1982). Cognitive psychology’s ambiguities: Some suggested remedies. Psychological Review, 89, 48-59.

Hetherington, E. M., \& Feldman, S. E. (1964). College cheating as a function of subject and situational variables. Journal of Educational Psychology, 55, 212-218.

Hirt, E. R., McDonald, H. E., \& Melton, R. J. (1996). Processing goals and the affectperformance link: Mood as main effect or mood as input? In L. L. Martin \& A. Tesser (Eds.), Striving and feeling: Interactions among goals, affect, and self-regulation (pp. 303-328). Hillsdale, NJ: Erlbaum.

Hocevar, D. (1980). Intelligence, divergent thinking, and creativity. Intelligence, 4, 25-40.

Horibe, F. (2001). Creating the innovation culture: Leveraging visionaries, dissenters and other useful troublemakers in your organization. New York: John Wiley \& Sons.

Hsee, C. K. (1995). Elastic justification: How tempting but task-irrelevant factors influence decisions. Organizational Behavior and Human Decision Processes, 62, 330-337. 
Hsee, C. K. (1996). Elastic justification: How unjustifiable factors influence judgments. Organizational Behavior and Human Decision Processes, 66, 122-129.

Johnson, C. D., \& Gormly, J. (1971). Achievement, sociability and task importance in relation to academic cheating. Psychological Reports, 28, 302.

Jordan, A.H., \& Monin, B. (2008). From sucker to saint: Moralization in response to self-threat. Psychological Science, 19(8), 683-689.

Kaufman, J. C., Baer, J., Cole, J. C., \& Sexton, J. D. (2008). A comparison of expert and nonexpert raters using the consensual assessment technique. Creativity Research Journal, $20,171-178$.

Kershner, J. R., \& Ledger, G. (1985). Effect of sex, intelligence, and style of thinking on creativity: A comparison of gifted and average IQ children. Journal of Personality and Social Psychology, 48, 1033-1040.

Kirton, M. (1976). Adaptors and innovators: a description and measure. Journal of Applied Psychology, 61(5), 622-629.

Kunda, Z. (1990). The case for motivated reasoning. Psychological Bulletin, 108(3), 480-498.

Lev, B. (2004). Sharpening the intangible edge. Harvard Business Review, June, 109-116.

Maddux, W. W., \& Galinsky, A. D. (2009). Cultural borders and mental barriers: The relationship between living abroad and creativity. Journal of Personality and Social Psychology, 96, 1047-1061.

Markman, K. D., Lindberg, M. J., Kray, L. J., \& Galinsky, A. D. (2007). Implications of counterfactual structure for creative generation and analytical problem solving. Personality and Social Psychology Bulletin, 33, 312-324. 
Mazar, N., Amir, O., \& Ariely, D. (2008). The dishonesty of honest people: A theory of selfconcept maintenance. Journal of Marketing Research, 45, 633-644.

McBarnet, D. (1988). Law, policy and legal avoidance. Journal of Law \& Society, 113.

McBarnet, D., \& Whelan, C. (1991). The elusive spirit of the law: Formalism and the struggle for legal control. Modern Law Review, 54, 6.

Mead, N., Baumeister, R. F., Gino, F., Schweitzer, M., \& Ariely, D. (2009). Too tired to tell the truth: Self-control resource depletion and dishonesty. Journal of Experimental Social Psychology, 45(3), 594-597.

Mednick, S. A. (1962). The associative basis of the creative process. Psychological Review, 69, $220-232$.

Monin, B. \& Miller, D. T. (2001). Moral credentials and the expression of prejudice. Journal of Personality and Social Psychology, 81, 33-43.

Monin, B., Sawyer, P., \& Marquez, M. (2008). The rejection of moral rebels: Resenting those who do the right thing. Journal of Personality and Social Psychology, 95(1), 76-93.

Mumford, M. D. \& Gustafson, S. B. (1988) Creativity Syndrome: Integration, application, and innovation. Psychological Bulletin, 103, 27-43.

Oldham, G. R., \& Cummings, A. (1996). Employee creativity: Personal and contextual factors at work. Academy of Management Journal, 39, 607-634.

Plucker, J. A., \& Renzulli, J. S. (1999). Psychometric approaches to the study of human creativity. In R. J. Sternberg (Ed.), Handbook of creativity (pp. 35-61). New York: Cambridge.

Raven, J., Raven, C., \& Court, J. H. (1998). Manual for Raven's progressive matrices and vocabulary scales. Oxford Psychologists Press Ltd, Oxford. 
Runco, M. A. (2004). Creativity. Annual Review of Psychology, 55, 657-687.

Sassenberg, K., \& Moskowitz, G. B. (2005). Don’t stereotype, think different! Overcoming automatic stereotype activation by mindset priming. Journal of Experimental Social Psychology, 41, 506-514.

Schaller, M. (2003). Ancestral environments and motivated social perception: Goal-like blasts from the evolutionary past. In S. J. Spencer, S. Fein., M. P. Zanna, \& J. M. Olson (Eds.), Motivated social perception (pp. 215-231). Mahwah, NJ: Erlbaum.

Schweitzer, M. E. \& Hsee, C. K. (2002). Stretching the truth: Elastic justification and motivated communication of uncertain information. The Journal of Risk and Uncertainty, 25, 185201.

Shalvi, S., Dana, J., Handgraaf, M.J.J \& De Dreu, C.K.W. (2011). Justified ethicality: Observing desired counterfactuals modifies ethical perceptions and behavior. Organizational Behavior and Human Decision Processes, 115, 181-190.

Shu, L. L., Gino, F., \& Bazerman, M. H. (2011). Dishonest deed, clear conscience: When cheating leads to moral disengagement and motivated forgetting. Personality and Social Psychology Bulletin, 37(4), 330-349.

Simonton, D. K. (2000). Creativity: Cognitive, personal, developmental, and social aspects. American Psychologist, 55(1), 151-158.

Simonton, D. K. (2003). Scientific creativity as constrained stochastic behavior: The integration of product, person, and process perspectives. Psychological Bulletin, 129, 475-494.

Smith, S. M., Ward, T. B., \& Finke, R. A. (1995). Cognitive processes in creative contexts. In S.M. Smith, T.B. Ward, \& R.A. Finke (Eds.). The creative cognition approach, Cambridge: MIT Press, p. 1-7. 
Snyder, M. L., Kleck, R. E., Strenta, A., \& Mentzer, S. J. (1979). Avoidance of the handicapped: An attributional ambiguity analysis. Journal of Personality and Social Psychology, 12, 2297-2306.

Spiro, R. J. \& Jehng, J. (1990). Cognitive flexibility and hypertext: Theory and technology for the non-linear and multidimensional traversal of complex subject matter. D. Nix \& R. Spiro (eds.), Cognition, Education, and Multimedia. Hillsdale, NJ: Erlbaum.

Sternberg, R. J. (2001). What is the common thread of creativity? Its dialectical relation to intelligence and wisdom. American Psychologist, 56, 360-362.

Sternberg, R. J. (Ed.) (1999a). Handbook of creativity. New York: Cambridge University Press.

Sternberg, R. J. (1999b). A propulsion model of creative contributions. Review of General Psychology, 3, 83-100.

Tenbrunsel, A. E., \& Messick, D. M. (2004). Ethical fading: The role of self-deception in unethical behavior. Social Justice Research, 17(2), 223-236.

Thompson, L. (2008). Making the team. 3rd edition. Upper Saddle River, NJ: Pearson Education, Inc.

Tierney, P., \& Farmer, S. M. (2002). Creative self-efficacy: Its potential antecedents and relationship to creative performance. Academy of Management Journal, 45, 1137-1148.

Zhou, J., \& Oldham, G. R. (2001). Enhancing creative performance: Effects of expected developmental assessment strategies and creative personality. Journal of Creative Behavior, 35, 151-167. 
Tables

Table 1

Descriptive statistics (on raw measures) and correlations (on z-scores of each measure), Pilot

Study

\begin{tabular}{|c|c|c|c|c|c|}
\hline & $\mathrm{M}$ & SD & 2 & 3 & 4 \\
\hline $\begin{array}{l}\text { 1. Ratings provided by managers for the level } \\
\text { of creativity required in each department }\end{array}$ & 7.10 & 1.94 & $.53 * * *$ & $.30 * *$ & $.46 * * *$ \\
\hline $\begin{array}{l}\text { 2. Ratings provided by employees for the } \\
\text { level of creativity required in their job }\end{array}$ & 4.84 & 1.55 & & $.20 *$ & $.24 *$ \\
\hline $\begin{array}{l}\text { 3. Ratings provided by employees for their } \\
\text { likelihood to behave dishonestly across the } \\
\text { eight behaviors }\end{array}$ & 2.58 & 1.05 & & & $.37 * * *$ \\
\hline $\begin{array}{l}\text { 4. Ratings provided by employees for their } \\
\text { likelihood to behave dishonestly across the } \\
\text { two dilemmas }\end{array}$ & 3.69 & 1.52 & & & \\
\hline
\end{tabular}

$* * * p<.001, * * p<.01, * p<.05$ 
Table 2

Descriptive statistics and correlations (using raw scores for each measure), Experiment 1

\begin{tabular}{|c|c|c|c|c|c|c|c|c|c|c|}
\hline & & M & SD & 1 & 2 & 3 & 4 & 5 & 6 & 7 \\
\hline \multirow{3}{*}{$\begin{array}{l}\text { Creative } \\
\text { personality }\end{array}$} & $\begin{array}{l}\text { 1. Gough's creative } \\
\text { personality }\end{array}$ & 11.24 & 2.81 & & & & & & & \\
\hline & $\begin{array}{l}\text { 2. Creative cognitive } \\
\text { style }\end{array}$ & 3.74 & 0.75 & $.54 * * *$ & & & & & & \\
\hline & $\begin{array}{l}\text { 3. Hocevar's creative } \\
\text { behavior inventory }\end{array}$ & 147.29 & 40.74 & $.45^{* * *}$ & $.54 * * *$ & & & & & \\
\hline \multirow[b]{2}{*}{ Intelligence } & 4. Cognitive & 1.22 & 1.10 & .003 & -.04 & -.04 & & & & \\
\hline & $\begin{array}{l}\text { Reflection Test score } \\
\text { 5. Mill vocabulary } \\
\text { test score }\end{array}$ & 6.49 & 1.67 & .001 & -.08 & .02 & $.30 * *$ & & & \\
\hline \multirow{3}{*}{ Tasks } & $\begin{array}{l}\text { 6. Cheating level on } \\
\text { problem solving task }\end{array}$ & 2.92 & 4.54 & $.53 * * *$ & $.35^{* *}$ & $.42 * * *$ & .04 & .04 & & \\
\hline & $\begin{array}{l}\text { 7. Cheating level on } \\
\text { multiple-choice task }\end{array}$ & 3.33 & 5.86 & $.31 * *$ & $.25^{*}$ & $.25^{*}$ & .02 & -.11 & $.62 * *$ & \\
\hline & $\begin{array}{l}\text { 8. Cheating level on } \\
\text { perceptual task }^{1}\end{array}$ & 71.95 & 23.38 & $.33 * *$ & $.23 *$ & $.25^{*}$ & .10 & .08 & $.34 * *$ & $.26^{*}$ \\
\hline
\end{tabular}

$* * * p<.001 ; * * p<.01 ; * p<.05$

Note. The dark rectangle depicts the relationship between the creativity measures and dishonesty. The dark square depicts the relationship between the intelligence measures and dishonesty.

${ }^{1}$ Cheating on the perceptual task is calculated as the number of times participants chose "more on the right" in ambiguous trials. 
Table 3

Descriptive statistics and correlations (on raw measures), Experiment 4

\begin{tabular}{lccccccc}
\hline & $\mathrm{M}$ & $\mathrm{SD}$ & & 2 & 3 & 4 & 5 \\
\cline { 2 - 5 } \cline { 5 - 7 } 1. Gough's creative personality & 2.18 & 1.62 & & $.44^{* * *}$ & $.33^{* * *}$ & .06 & $.19^{*}$ \\
2. Creative cognitive style & 5.01 & 1.14 & & & $.43^{* * * *}$ & $.23 * *$ & $.45^{* * *}$ \\
$\begin{array}{l}\text { 3. Hocebar's Creative behavior } \\
\text { inventory }\end{array}$ & 147.01 & 50.35 & & & $.36^{* * *}$ & $.22^{* *}$ \\
4. Narcissism & & & & & & \\
5. Performance on the RAT & 8.25 & 4.13 & & & & & \\
\hline
\end{tabular}

$* * * p<.001, * * p<.01, * p<.05$

Table 4

Regression analysis predicting self-reported outcome on the die roll, Experiment 4

\begin{tabular}{lccccc}
\hline & \multicolumn{1}{c}{$\mathrm{B}$} & $\mathrm{SE}$ & & $\beta$ & \multicolumn{1}{c}{$\mathrm{t}$} \\
\cline { 2 - 3 } \cline { 5 - 6 } Narcissism & -.026 & .107 & & -.018 & -.243 \\
Justifications & .568 & .205 & & .197 & $2.78^{* *}$ \\
Creative personality & 1.046 & .186 & & .561 & $5.61 * * *$ \\
Creative personality X & -.539 & .265 & & -.201 & $-2.04 *$ \\
Justifications & & & & & \\
& $R^{2}=.23$ & & & & \\
\hline
\end{tabular}

$* * * p<.001, * * p<.01, * p<.05$ 
Table 5

Descriptive statistics and correlations for variables assessing creativity (on raw measures),

Experiment 5

\begin{tabular}{lccccc}
\hline & $\mathrm{M}$ & $\mathrm{SD}$ & & 2 & 3 \\
\cline { 2 - 3 } \cline { 5 - 6 } 1. Gough's creative personality & 10.08 & 3.77 & & $.46^{* * *}$ & $.35^{* * *}$ \\
2. Creative cognitive style & 3.56 & 0.76 & & $.33^{* * *}$ \\
$\begin{array}{l}\text { 3. Hocebar's Creative behavior } \\
\text { inventory }\end{array}$ & 87.78 & 54.12 & & \\
\hline
\end{tabular}

$* * * p<.001, * * p<.01, * p<.05$

Table 6

Moderated regression analyses, Experiment 5

\begin{tabular}{|c|c|c|c|c|}
\hline & \multicolumn{3}{|c|}{$\begin{array}{c}\text { Performance on the candle } \\
\text { task }\end{array}$} & \\
\hline & $\mathrm{B}$ & $\mathrm{SE}$ & Wald & $\mathrm{B}$ \\
\hline Mindset $(1=$ creative, $0=$ neutral $)$ & 1.44 & .461 & $9.79 * *$ & 1.18 \\
\hline Creative personality & 1.16 & .497 & $5.43^{*}$ & .93 \\
\hline Creative personality X Mindset & -1.31 & .606 & $4.65^{*}$ & -1.12 \\
\hline \multicolumn{4}{|c|}{ Nagelkerke $R^{2}=.179$} & Nagel \\
\hline \multicolumn{5}{|l|}{$* * * p<.001, * * p<.01, * p<.05$} \\
\hline & \multicolumn{4}{|c|}{ Extent of cheating } \\
\hline & $\mathrm{B}$ & SE & $\beta$ & $\mathrm{t}$ \\
\hline Mindset $(1=$ creative, $0=$ neutral $)$ & 1.53 & .64 & .23 & $2.41 *$ \\
\hline Creative personality & 1.24 & .62 & .28 & $2.00 *$ \\
\hline Creative personality X Mindset & -1.67 & .84 & -.28 & $-1.99 *$ \\
\hline $\begin{array}{l}R^{2}=.09 \\
F(3,104)=3.43 *\end{array}$ & & & & \\
\hline
\end{tabular}




\section{Figure Captions}

Figure 1. Example of perceptual task, Experiment 1.

Figure 2. Duncker Candle Problem, Experiment 2.

Figure 3. Self-reported outcome of die roll by condition, Experiment 3.

Figure 4. Simple slopes for self-reported outcome of die roll, Experiment 4.

Figure 5. Simple slopes for the extent of cheating, Experiment 5. 
Figure 1.

(a) Unambiguous trial

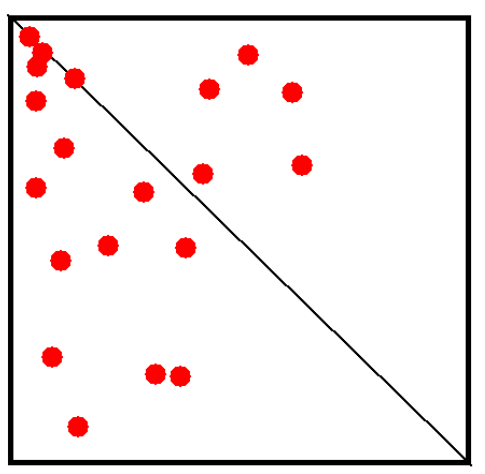

(b) Ambiguous trial

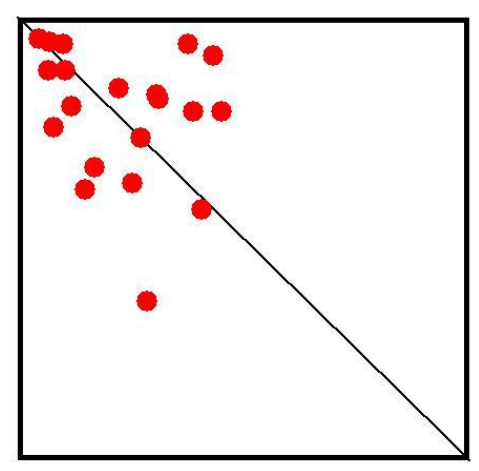

Figure 2.

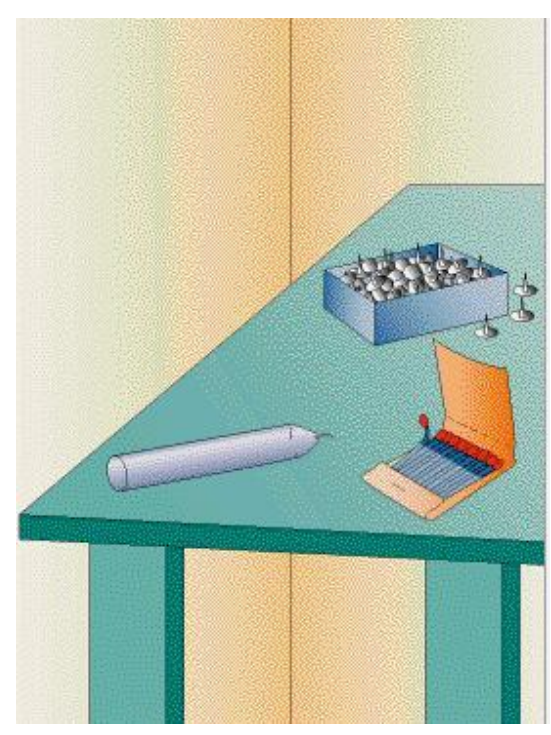


Figure 3.

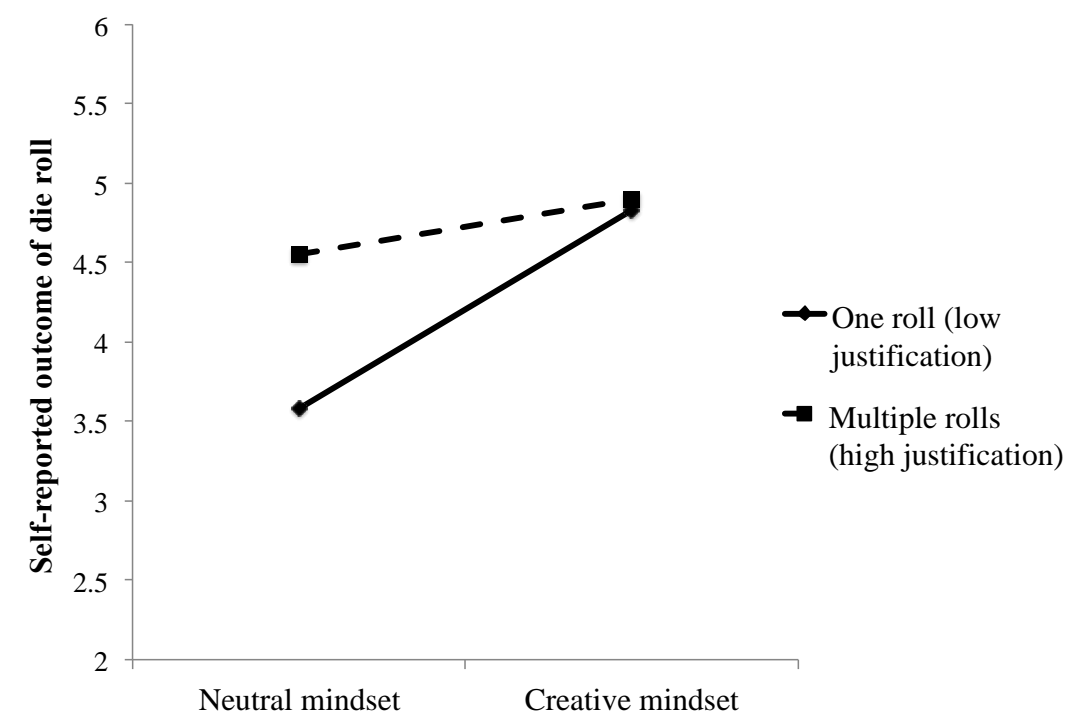

Figure 4.

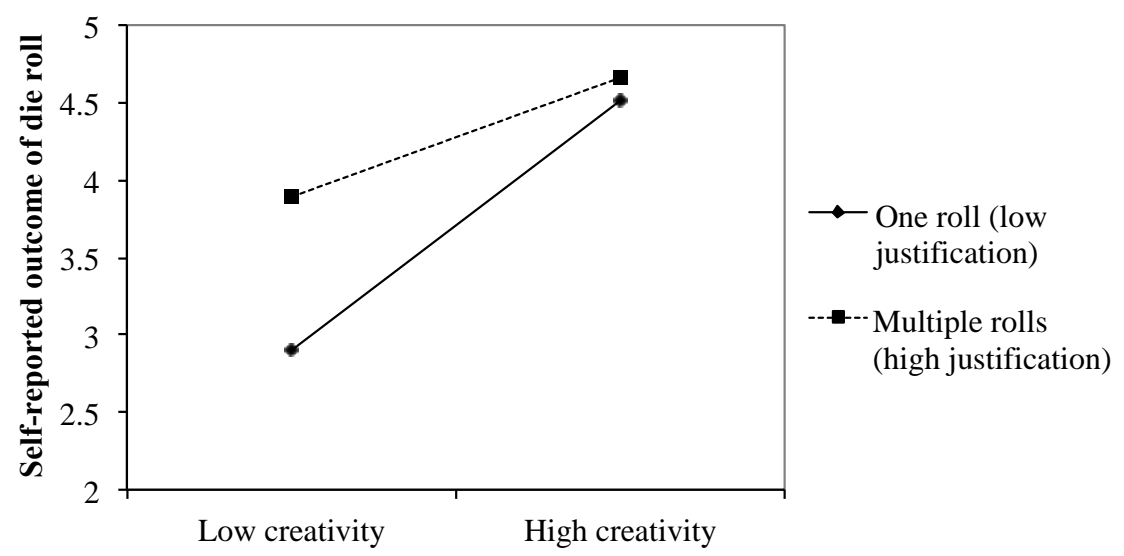


Figure 5.

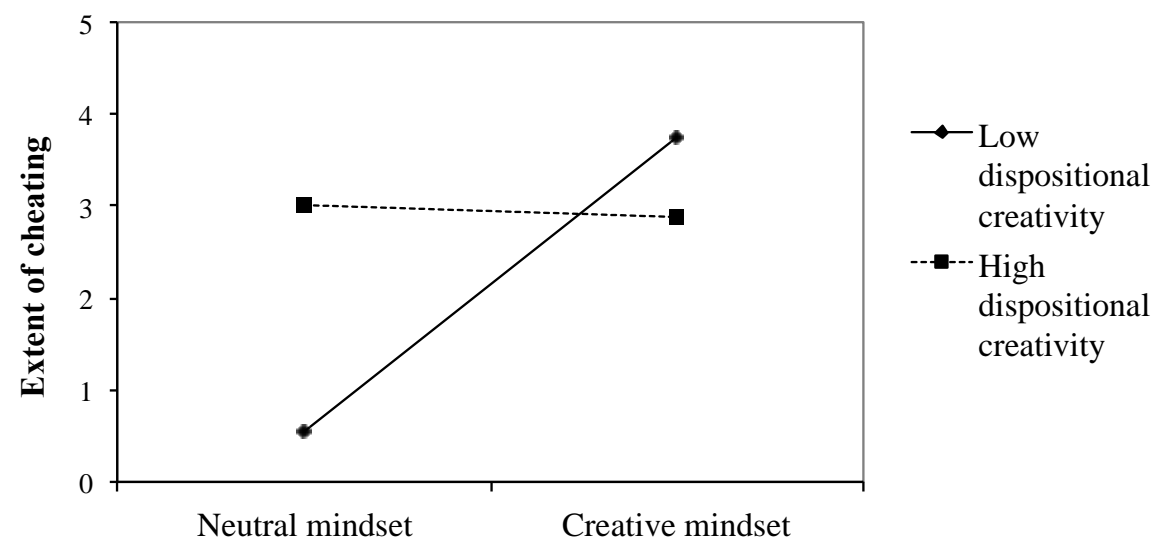

